\title{
Stability Indicating Assay Method Development and Validation for Tenofovir Alafenamide Fumarate by RP-HPLC
}

\section{Aggarwal NN, Bhat $\mathrm{KI}^{*}$ and Jacob JT}

Department of Pharmaceutical Chemistry, NGSM Institute of Pharmaceutical Sciences of Nitte-Deemed to be University, Paneer, Deralakatte, Mangalore-575 018, Karnataka, India

\begin{abstract}
Aim: Development and validation of a stability indicating assay method for Tenofovir Alafenamide Fumarate tablets ( $25 \mathrm{mg}$ strength) by RP-HPLC.

Methodology: An efficient experimental design based on systematic scouting of all key components of the RP-HPLC method and stress studies were performed. The separations were carried out on a C-18 reversed phase column (Inertsil ODS, $100 \times 4.6 \mathrm{~mm}, 5 \mu$ ) using a mobile phase consisting of pH 6.0 ammonium acetate buffer and a solvent mixture (30:70) of ACN and THF in the ratio of 990:10 (Mobile phase A) and 500:500 (Mobile phase B) in a gradient elution mode at a flow rate of $1.50 \mathrm{~mL} / \mathrm{min}$ and column oven temperature of $45^{\circ} \mathrm{C}$. The wavelength of detection was $260 \mathrm{~nm}$. Analytical validation parameters such as selectivity, linearity, accuracy, precision and robustness were evaluated as per ICH Q2 (R1) guidelines.
\end{abstract}

Results: USP plate count and the USP tailing factor for the pure drug peak was found to be 9082 and 0.98 respectively which are well within the acceptance criteria. Forced degradation studies performed revealed that none of the degradants generated interfered with the pure drug peak.

Conclusion: The proposed method can hence be used for routine analysis of Tenofovir Alafenamide Fumarate.

Keywords: RP-HPLC; Tenofovir alafenamide fumarate; Validation

\section{Introduction}

Tenofovir Alafenamide Fumarate (TAF) belongs to the class of nucleotide reverse transcriptase inhibitor (NRTI). It is a novel ester prodrug of the antiretroviral Tenofovir. It is chemically called as $(2 \mathrm{E})-$ but-2-enedioic acid; bis(propan-2-yl (2S)-2-\{[(S)-(\{[(2R)-1-(6-amino9H-purin-9-yl)propan-2yl] oxy\}methyl)(phenoxy)phosphoryl]amino\} propanoate). It has a molecular formula of $\mathrm{C}_{23} \mathrm{H}_{31} \mathrm{~N}_{6} \mathrm{O}_{7} \mathrm{P}$ and a molecular weight- $476.47 \mathrm{~g} / \mathrm{mol}$. It has the following structure (Figure 1) [1].

\section{Experimental}

\section{Chemicals and reagents}

The reference standards as well as the test samples and placebos were provided by Mylan laboratories. Ammonium acetate, orthophosphoric acid, Hydrochloric acid, (AR grade); Water, methanol, Tetrahydrofuran (THF) and Acetonitrile (ACN) of HPLC grade were used. The $0.45 \mu \mathrm{m}$ pump nylon, PVDF filter were obtained from advanced micro devices (Ambala Cantt, India).

\section{Instrumentation}

The development and validation of the method was carried out in Agilent Technology HPLC with PDA detector, using Inertsil ODS column $(100 \times 4.6 \mathrm{~mm}, 5 \mu \mathrm{m})$. Recording of the data was done using Empower 2 and Empower 3 software.

\section{Chromatographic conditions}

After numerous trials using different combinations of solvents, the mobile phase was optimized to be

Mobile Phase A: Ammonium acetate buffer ( $\mathrm{pH}$ 6.0): $70 \% \mathrm{THF}+30 \% \mathrm{ACN}(990: 10)$ and

Mobile Phase B: Ammonium acetate buffer ( $\mathrm{pH}$ 6.0):

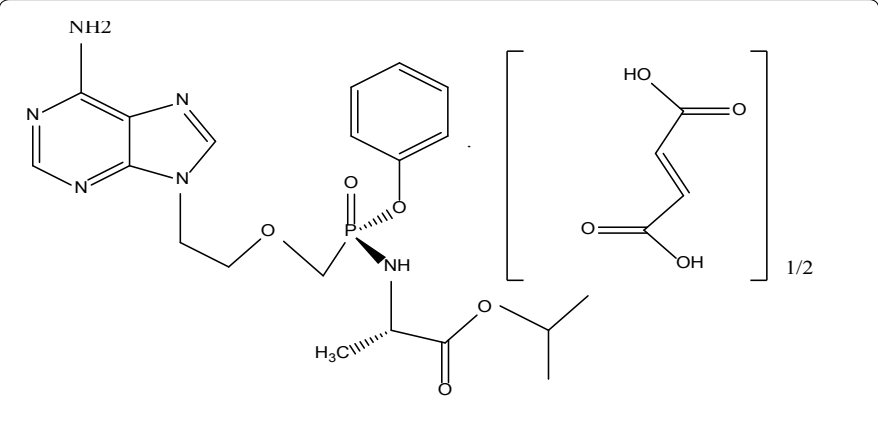

Figure 1: Structure of tenofovir alafenamide fumarate.

$70 \% \mathrm{THF}+30 \% \mathrm{ACN}(500: 500)$.

The chromatographic separation was carried out using Inertsil ODS column $(100 \times 4.6 \mathrm{~mm}, 5 \mu \mathrm{m})$ at a flow rate of $1.50 \mathrm{~mL} / \mathrm{min}$ and column oven temperature of $45^{\circ} \mathrm{C}$. The sample temperature was set at $8^{\circ} \mathrm{C}$. The wavelength of detection was $260 \mathrm{~nm}$.

$100 \%$ methnol was optimized as diluent- 1 and $50 \%$ aqueous methanol was optimized as diluent-2.

*Corresponding author: Natasha Naval Aggarwal, Department of Pharmaceutical Chemistry, NGSM Institute of Pharmaceutical Sciences of Nitte-Deemed to be University, Paneer, Deralakatte, Mangalore- 575 018, Karnataka, India, Tel No: +91 7795578072; E-mail: aggarwalnatasha01@gmail.com

Received December 05, 2018; Accepted December 19, 2018; Published December 26, 2018

Citation: Aggarwal NN, Bhat KI, Jacob JT (2018) Stability Indicating Assay Method Development and Validation for Tenofovir Alafenamide Fumarate by RP-HPLC. Pharm Anal Acta 9: 601. doi: 10.4172/2153-2435.1000601

Copyright: (c) 2018 Aggarwal NN, et al. This is an open-access article distributed under the terms of the Creative Commons Attribution License, which permits unrestricted use, distribution, and reproduction in any medium, provided the original author and source are credited. 


\begin{tabular}{|c|c|}
\hline Column & $\begin{array}{c}\text { Inertsil ODS-3V column }(4.6 \mathrm{~mm} \times 100 \mathrm{~mm}) \\
\text { with 5 } \mu \mathrm{m}\end{array}$ \\
\hline Mobile phase & $\begin{array}{c}\text { Mobile Phase A: Ammonium acetate buffer } \\
(\mathrm{pH} 6.0): 70 \% \mathrm{THF}+30 \% A C N \\
\text { Mobile Phase B: Ammonium acetate buffer } \\
(\mathrm{pH} 6.0): 70 \% \text { THF+30\%ACN (500:500) }\end{array}$ \\
\hline Injection Volume & $10 \mu \mathrm{L}$ \\
\hline Flow rate & $1.5 \mathrm{~mL} / \mathrm{min}$ \\
\hline Column temperature & $45^{\circ} \mathrm{C}$ \\
\hline Sample temperature & $8^{\circ} \mathrm{C}$ \\
\hline Detection wavelength & $260 \mathrm{~nm}$ \\
\hline Run Time & 15 minutes \\
\hline
\end{tabular}

Table 1: Optimized chromatographic parameters.

For analysis of forced degradation samples, the PDA detector was used in scan mode with a scan range of 200-400 $\mathrm{nm}$. The peak homogeneity was expressed in terms of peak purity and was obtained spectral analysis report using previously mentioned software (Table 1).

\section{Tenofovir alafenamide fumarate standard stock solution preparation}

Accurately weighed $57 \mathrm{mg}$ of Tenofovir Alafenamide Fumarate was taken in a $100 \mathrm{~mL}$ dry volumetric flask and was sonicated to dissolve after adding about $80 \mathrm{~mL}$ of diluent-1. It was then made up to mark with diluent-1.

\section{Tenofovir alafenamide fumarate standard solution preparation}

From the above prepared stock solution, $5 \mathrm{~mL}$ was pipetted into a $25 \mathrm{~mL}$ volumetric flask and made up to mark with diluent- 2 to get a final concentration of $100 \mathrm{ppm}$.

\section{Analysis of formulation}

Firstly, the average weight of twenty tablets was taken. Ten tablets were then taken randomly in a $250 \mathrm{~mL}$ volumetric flask. To this, about $30 \mathrm{~mL}$ of water was added to disintegrate the coating of the tablet. Thereafter, about $170 \mathrm{~mL}$ of diluent- 1 was added and the sample was sonicated for 30 minutes. It was then made up to mark with diluent-1 and centrifuged. From the supernatant, $5 \mathrm{~mL}$ was taken in a $50 \mathrm{~mL}$ volumetric flask and then made up to mark with diluent-2.The solution was then filtered through $0.45 \mu \mathrm{m}$ PVDF filter. (Sample concentration: $100 \mathrm{ppm}$ ) (Figure 2).

\section{Calculations}

$$
\begin{aligned}
& \mathrm{AT} \times \mathrm{WT} \times \mathrm{V} 1 \times 25 \times \mathrm{V} 4 \times 476.5 \times \mathrm{P} \times \mathrm{AWs} \\
& \% \text { Assay of } \mathrm{TAF}=--100 \times \mathrm{LC} \\
& \mathrm{ST} \times 100 \times \mathrm{V} 2 \times \mathrm{WS} \times \mathrm{V} 3 \times 534.5 \times 100 \\
& \text { Where, }
\end{aligned}
$$

$\mathrm{AT}=$ Average peak area of Tenofovir Alafenamide Fumarate from test preparation

$\mathrm{ST}=$ Average peak area of Tenofovir Alafenamide Fumarate from standard preparation

WT $=$ Weight of Tenofovir Alafenamide Fumarate standard (mg), for standard preparation

LC= Label claim of Tenofovir Alafenamide Fumarate $(\mathrm{mg})$, per unit dose (25 mg)

$\mathrm{P}=$ Potency of Tenofovir Alafenamide Fumarate standard in \%

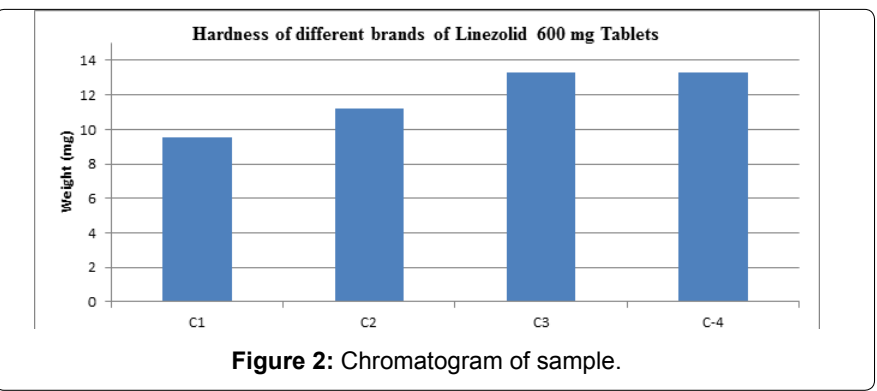

$\mathrm{w} / \mathrm{w}$, on as is basis

WS= Weight of sample taken in 'mg' for test preparation

AWs $=$ Average weight of Tenofovir Alafenamide Fumarate tablets (mg)

476.5= Molecular weight of Tenofovir Alafenamide

534.5= Molecular weight of Tenofovir Alafenamide Fumarate

$\mathrm{V} 1, \mathrm{~V} 2=$ Standard dilutions

V3, V4= Sample dilutions below

The chromatogram obtained from the optimized method is shown

\section{Forced degradation studies}

The International Conference on Harmonization ( $\mathrm{ICH}$ ) guideline entitled stability testing of new drug substances and products needs that stress testing is carried out to demonstrate the inherent stability characteristics of the active substance [2]. To evaluate the interference from degradation products, forced degradation study has been conducted by stressing simultaneously placebo, standard and drug product under the following stress conditions (Figure 3 and Table 2) [3].

\section{TAF has 10 known impurities.}

Standard solution preparation: Standard solution of $100 \mathrm{ppm}$ of Tenofovir alafenamide fumerate was prepared and injected into the HPLC system.

Acid degradation: $156 \mathrm{mg}$ of sample was accurately weighed and transferred into $25 \mathrm{~mL}$ volumetric flask. Added to it $2.5 \mathrm{~mL}$ of $0.1 \mathrm{~N}$ $\mathrm{HCL}$ and kept on bench top for 2 minutes. Added $2.5 \mathrm{~mL}$ of $0.1 \mathrm{~N} \mathrm{NaOH}$ and shaken for the neutralization step to take place. Thereafter, $10 \mathrm{~mL}$ diluent-1 was added and sonicated for 30 minutes. It was then made up to mark with diluent- 1 and centrifuged. $5 \mathrm{~mL}$ from the supernatant was pipetted into a $50 \mathrm{~mL}$ volumetric flask and made up to mark with diluent-2. Placebo and API equivalent to the amount present in one tablet (131 mg and $25 \mathrm{mg}$ respectively) was treated in a similar manner and analyzed as per the method. The resulted degradation was $9.6 \%$ (Figure 4).

Base degradation: Weighed accurately about $156 \mathrm{mg}$ of sample and transferred into $25 \mathrm{~mL}$ volumetric flask. Added to it $0.5 \mathrm{~mL}$ of $0.05 \mathrm{~N}$ $\mathrm{NaOH}$ and kept on bench top for 2 minutes. Added $0.5 \mathrm{~mL}$ of $0.1 \mathrm{~N}$ HCL and shaken for the neutralization step to take place. Thereafter, 10 $\mathrm{ml}$ diluent- 1 was added and sonicated for 30 minutes. It was then made up to mark with diluent- 1 and centrifuged. $5 \mathrm{~mL}$ from the supernatant was pipetted into a $50 \mathrm{~mL}$ volumetric flask and made up to mark with diluent-2. Placebo and API equivalent to the amount present in one tablet (131 $\mathrm{mg}$ and $25 \mathrm{mg}$ respectively) was treated in a similar manner 


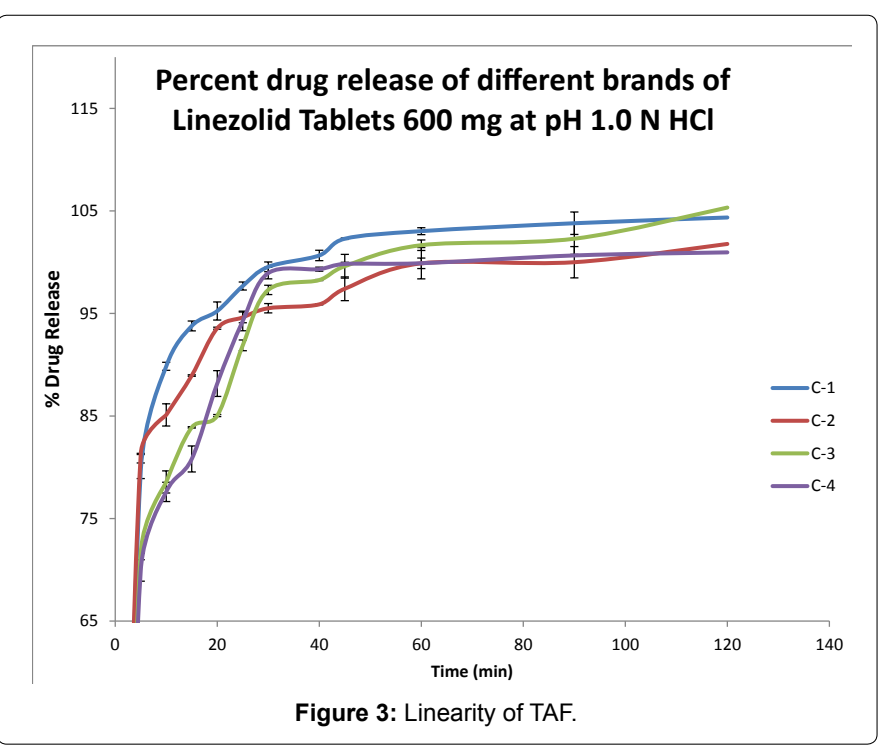

\begin{tabular}{|c|c|c|}
\hline Sr. No. & Name of impurities & $\begin{array}{c}\text { RT of Impurities } \\
\text { from } \\
\text { Known Impurity } \\
\text { Injection (min) }\end{array}$ \\
\hline & PMPA Anhydro Impurity & 0.671 \\
\hline TAF impurity & 0.713 \\
\hline Mono Phenyl PMPA Impurity & 1.233 \\
\hline PMPA monoamidate impurity & 1.241 \\
\hline Methyl Impurity & 2.901 \\
\hline Ethyl impurity & 5.198 \\
\hline PMPA bisamidate Impurity & 5.424 \\
\hline Diastereomer- 3 impurity & 6.171 \\
\hline Diastereomer- 2 impurity & 6.173 \\
\hline n-Propyl Impurity & 8.534 \\
\hline
\end{tabular}

Table 2: Results of impurities interference.

\begin{tabular}{|c|c|c|}
\hline $\begin{array}{c}\text { System Suitability } \\
\text { Parameters }\end{array}$ & Observed Value & Acceptance Criteria \\
\hline USP Plate count & $\mathbf{9 0 8 2}$ & $" 2000$ \\
\hline USP Tailing factor & $\mathbf{0 . 9 8}$ & $" 2.0$ \\
\hline $\begin{array}{c}\text { \% Relative standard } \\
\text { deviation* }\end{array}$ & $\mathbf{0 . 0 5}$ & $" 2.0$ \\
\hline \multicolumn{2}{|c|}{ "Six replicate injections "Not less than "'Not more than } \\
\hline
\end{tabular}

Table 3: Results of system suitability.

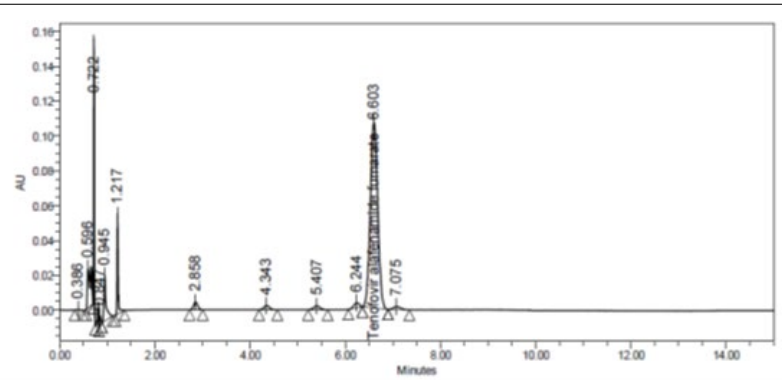

Figure 4: Typical chromatogram of standard preparation spiked with known impurities (1\% spiking)

and analyzed as per the method.

TAF degradation was reported as $8.7 \%$ (Figure 5).

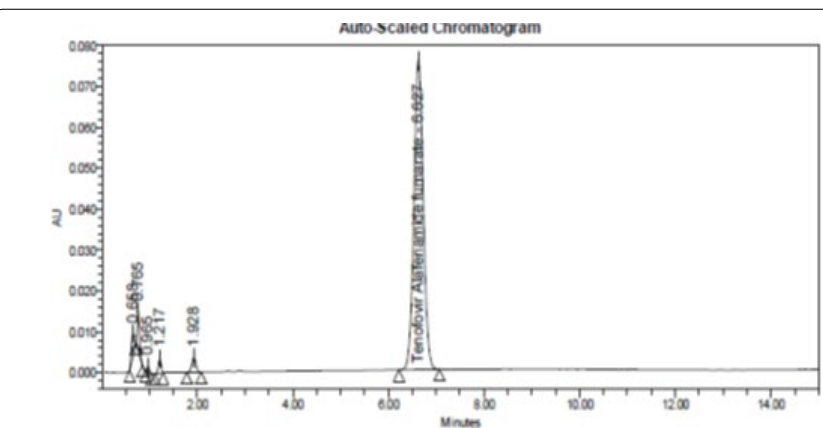

Figure 5: Chromatogram of acid degradation sample.

Oxidative degradation: Weighed accurately about $156 \mathrm{mg}$ of sample and transferred into $25 \mathrm{~mL}$ volumetric flask. Added to it $2.5 \mathrm{~mL}$ of $30 \% \mathrm{H}_{2} \mathrm{O}_{2}$ and kept on bench top for 3.5 hours. Thereafter, $10 \mathrm{~mL}$ diluent- 1 was added and sonicated for 30 minutes. It was then made up to mark with diluent- 1 and centrifuged. $5 \mathrm{ml}$ from the supernatant was pipetted into a $50 \mathrm{~mL}$ volumetric flask and made up to mark with diluent-2. Placebo and API equivalent to the amount present in one tablet ( $131 \mathrm{mg}$ and $25 \mathrm{mg}$ respectively) was treated in a similar manner and analyzed as per the method.

Oxidative degradation of $8.4 \%$ was recorded (Figure 6).

Hydrolysis degradation: Weighed accurately about $156 \mathrm{mg}$ of sample and transferred into $25 \mathrm{~mL}$ volumetric flask. Added to it $2.5 \mathrm{~mL}$ of $\mathrm{H}_{2} \mathrm{O}$ and kept at $80^{\circ} \mathrm{C}$ for 3.5 hours. Thereafter, $10 \mathrm{~mL}$ diluent- 1 was added and sonicated for 30 minutes. It was then made up to mark with diluent- 1 and centrifuged. $5 \mathrm{~mL}$ from the supernatant was pipetted into a $50 \mathrm{~mL}$ volumetric flask and made up to mark with diluent-2. Placebo and API equivalent to the amount present in one tablet $(131 \mathrm{mg}$ and 25 $\mathrm{mg}$ respectively) was treated in a similar manner and analyzed as per the method.

Hydrolysis degradation of $18.6 \%$ was achieved (Figure 7).

Humidity degradation: Weighed accurately $156 \mathrm{mg}$ of sample exposed to $40^{\circ} \mathrm{C} / 5 \% \mathrm{RH}$ for 7 days and transferred into $25 \mathrm{~mL}$ volumetric flask. Thereafter, $10 \mathrm{~mL}$ diluent-1 was added and sonicated for 30 minutes. It was then made up to mark with diluent-1 and centrifuged. $5 \mathrm{~mL}$ from the supernatant was pipetted into a $50 \mathrm{~mL}$ volumetric flask and made up to mark with diluent-2. Placebo and API equivalent to the amount present in one tablet (131 $\mathrm{mg}$ and $25 \mathrm{mg}$ respectively) was treated in a similar manner and analyzed as per the method.

\section{$7.4 \%$ of the drug degraded (Figure 8 ).}

Thermal degradation: Weighed accurately $156 \mathrm{mg}$ of sample exposed to $105^{\circ} \mathrm{C}$ for 3 hours and transferred into $25 \mathrm{~mL}$ volumetric flask. Thereafter, $10 \mathrm{~mL}$ diluent-1 was added and sonicated for 30 minutes. It was then made up to mark with diluent- 1 and centrifuged. $5 \mathrm{~mL}$ from the supernatant was pipetted into a $50 \mathrm{~mL}$ volumetric flask and made up to mark with diluent-2. Placebo and API equivalent to the amount present in one tablet ( $131 \mathrm{mg}$ and $25 \mathrm{mg}$ respectively) was treated in a similar manner and analyzed as per the method.

This resulted in $6.9 \%$ degradation (Figure 9).

\section{Method Validation}

\section{System suitability}

System suitability testing is an important segment of any analytical procedure [4]. The rationale of the test is the fact that electronics analytical operations, equipments and sample to be analyzed form 
Page 4 of 6
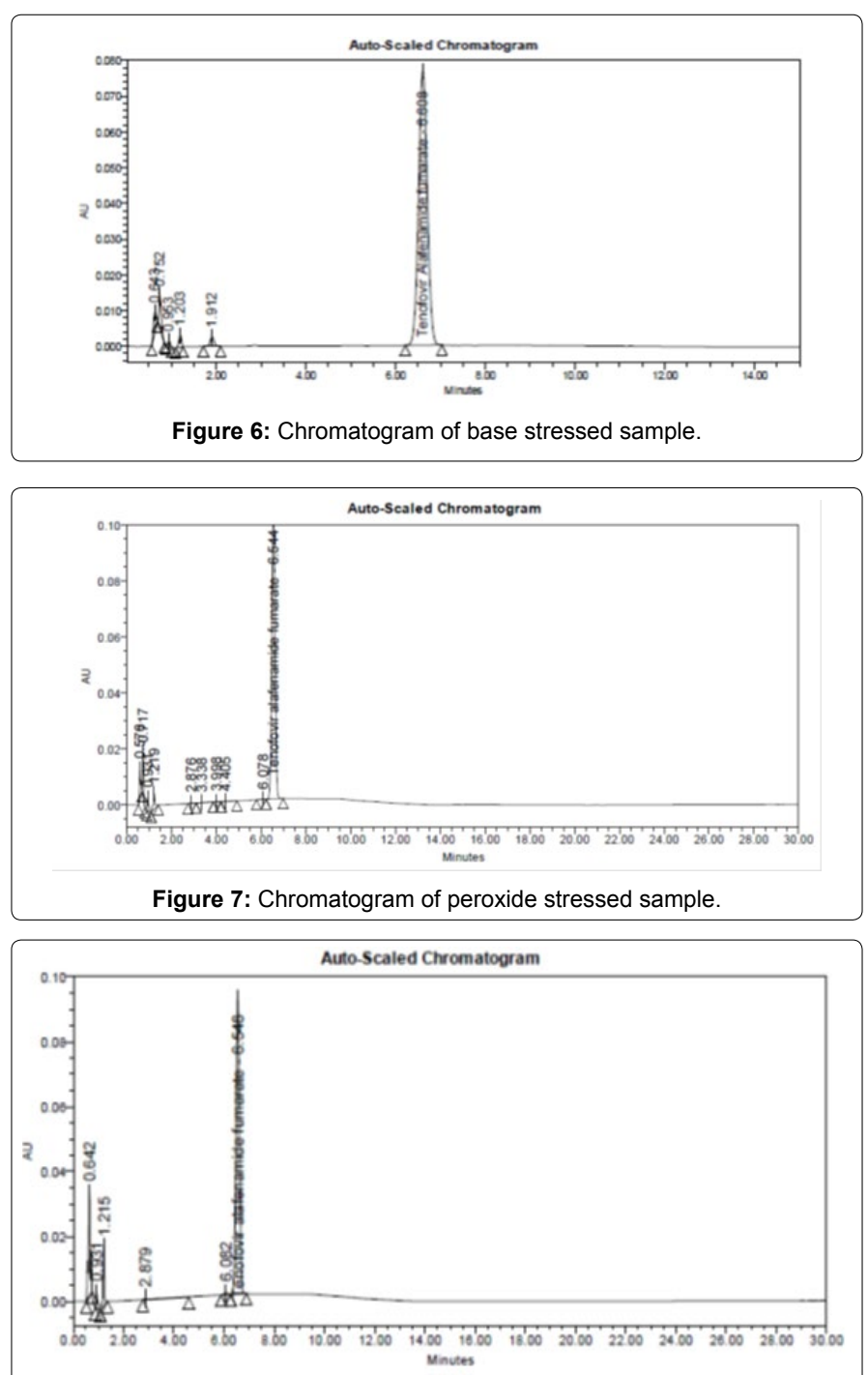

Figure 8: Chromatogram of hydrolysis stressed sample.

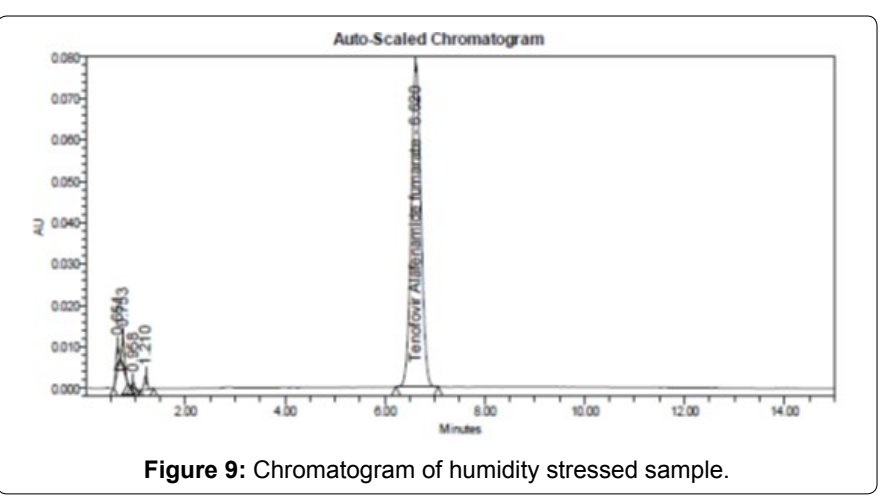

a vital system that can be evaluated as such [5]. System Suitability was determined by preparing and injecting standard solution in six replicates (Table 3).

\section{Linearity}

Linearity of the method has been studied across $10 \%$ to $150 \%$ of working concentration, using standard preparation [6]. Linearity graph has been plotted between response and concentration (Table 4 and

\begin{tabular}{|c|c|c|c|}
\hline Solution & $\begin{array}{c}\text { Concentrated } \\
(\boldsymbol{\mu} \mathbf{g} / \mathbf{m L})\end{array}$ & Area & Area (Linear Fit) \\
\hline 1 & 10.132 & 119331 & 118736.2113 \\
\hline 2 & 50.662 & 597860 & 596486.7824 \\
\hline 3 & 75.994 & 893509 & 895089.7301 \\
\hline 4 & 101.325 & 1192185 & 1193680.89 \\
\hline 5 & 121.59 & 1431648 & 1432556.176 \\
\hline 6 & 151.987 & 1792880 & 1790863.21 \\
\hline
\end{tabular}

Table 4: Linearity Data of Tenofovir.

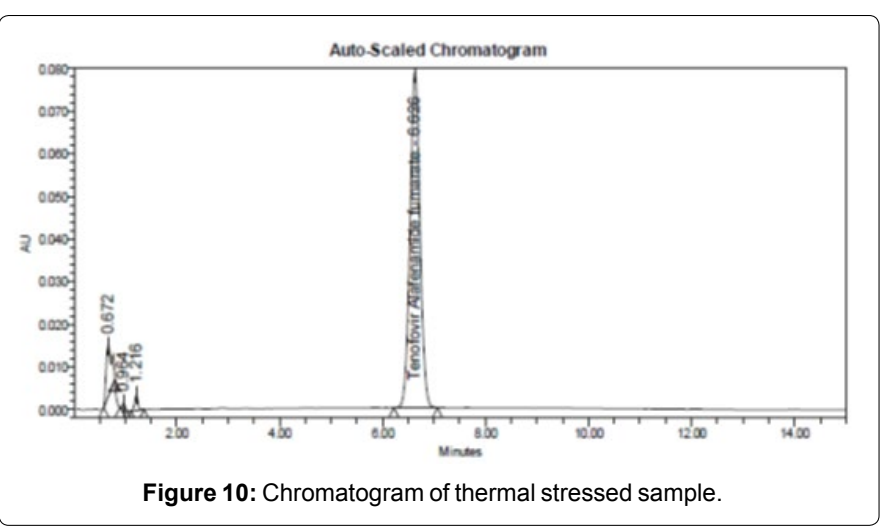

Figure 10).

\section{Precision}

System precision: System precision has been established by injecting six replicates of standard preparation. \% RSD shall be calculated for area responses (Table 5).

Method precision (Repeatability): Method precision has been determined by injecting six test preparations, representing a single batch to determine the Assay. \%RSD shall be calculated for observed results (Table 6).

\section{Accuracy}

A study of recovery was conducted for TAF intact tablet from about $50 \%$ to $150 \%$ of the initial assay concentration. Sample solutions were prepared in triplicate for each level and analyzed as per test method [7]. The individual \% recovery, \%average recovery and \% RSD for recovery at each level were calculated (Table 7).

\section{Range}

The range of an analytical procedure is the interval between the upper and lower concentration (amounts) of analyte in the sample (including these concentrations) for which it has been demonstrated that the analytical procedure has a suitable level of precision, accuracy and linearity [7]. The range was confirmed as $10 \%$ to $150 \%$ of the test concentration for TAF.

\section{Robustness}

Method robustness has been determined by making changes in the chromatographic parameters and sample preparation parameters [8]. The assay value determined for the same sample under original and robustness conditions depicts that the developed method was robust for effect of changed column temperature $\left( \pm 5^{\circ} \mathrm{C}\right)$, $\mathrm{pH}$ of the mobile phase $( \pm 0.2)$, organic \& aqueous variation in the mobile phase and impact of flow rate $( \pm 0.2 \mathrm{ml} / \mathrm{min})$. The evaluation was based on the system suitability parameters such as tailing factor, retention time, and theoretical plates. 
Page 5 of 6

\begin{tabular}{|c|c|}
\hline \multirow{2}{*}{ Injection No } & System precision (Peak area) \\
\cline { 2 - 2 } & TAF \\
\hline 2 & 1126672 \\
\hline 3 & 1126954 \\
\hline 4 & 1126811 \\
\hline 5 & 1127849 \\
\hline 6 & 1130718 \\
\hline Mean & 1126872 \\
\hline \%RSD* & 1127801 \\
\hline & \\
\hline
\end{tabular}

Table 5: System precision results.

\begin{tabular}{|c|c|c|}
\hline \multirow{2}{*}{ Sample No } & Area Count & (\% Assay) \\
\hline 1 & TAF & \\
\hline 2 & 1135522 & 101.9 \\
\hline 3 & 1132359 & 101.8 \\
\hline 4 & 1133270 & 101.8 \\
\hline 5 & 1130741 & 101.8 \\
\hline 6 & 1132992 & 101.9 \\
\hline & 1134736 & 101.9 \\
\hline & Mean & 101.85 \\
\hline & \%RSD* & 0.05 \\
\hline & "n & \\
\hline
\end{tabular}

Table 6: Method precision results.

\section{Results and Discussion}

\section{Optimization of chromatographic conditions}

In recent years an ART (antiretroviral) therapy has been developed, which includes single or combination therapy by antiviral drug [9]. The present investigation has been reported with an intention to develop a new validated method for the estimation of Tenofovir Alafenamide Fumarate tablets of strength $25 \mathrm{mg}$ by RP-HPLC method using a photo diode array detector. Literature reveals that there are no analytical methods reported for the estimation Tenofovir Alafenamide Fumarate individually by RP-HPLC method. To develop a stability-indicating method different makes of C18, C8 column (Xterra, Hypersil and Thermosil) and different mobile phases containing buffers ( $\mathrm{pH} \mathrm{2-6)}$ methanol as well as acetonitrile in different ratios were tried but failed to get optimum peak shape and freedom from impurity interference. This challenge was met by using $0.03 \mathrm{M}$ Ammonium acetate buffer (adjusted to $\mathrm{pH} 6$ by glacial acetic acid): organic modifier $(99: 1 \% \mathrm{v} / \mathrm{v})$ as mobile phase $\mathrm{A}$ and $\mathrm{pH} 6,0.03 \mathrm{M}$ ammonium acetate buffer: organic modifier $(50: 50 \% \mathrm{v} / \mathrm{v})$ as mobile phase $\mathrm{B}$ where optimum resolution and good symmetric peaks were observed by using Inertsil C18 (4.6 mm $\times$ $100 \mathrm{~mm}, 5 \mu \mathrm{m}$ ) analytical column in gradient mode at a flow rate of 1.5 $\mathrm{mL} / \mathrm{min}$ and column temperature at $45^{\circ} \mathrm{C}$. Under the above optimized conditions, the retention time reported for formulation was $6.5 \mathrm{~min}$. The linearity of an analytical procedure was demonstrated by preparing and analyzing the standard preparation at five different concentrations of (10-150 ppm). The calibration curve constructed for Tenofovir by plotting the peak area versus concentration yielded coefficient of regression $\mathrm{R}_{2}=0.99996$. The mean recovery value was 99.9 . The robustness study and percentage of assay of the formulation were found within limit as per ICH Guidelines .The theoretical plates were more than 2500 and tailing factor was less than 1.5. Specificity of the method was proved since the chromatograms of blank, placebo solution do not show any interference at the retention time of Tenofovir. Therefore, the developed method was free from the inference of diluents as well as the excipients used in the formulation.

\begin{tabular}{|c|c|c|c|c|}
\hline $\begin{array}{l}\% \text { Level } \\
\text { Spiked }\end{array}$ & Sample No. & $\%$ Recovery & $\begin{array}{c}\% \text { Recovery } \\
\text { Mean }\end{array}$ & $\%$ RSD \\
\hline \multirow{3}{*}{50} & 1 & 100.1 & \multirow{3}{*}{101.03} & \multirow{3}{*}{1.35} \\
\hline & 2 & 102 & & \\
\hline & 3 & 100.4 & & \\
\hline \multirow{3}{*}{100} & 1 & 101.9 & \multirow{3}{*}{101.83} & \multirow{3}{*}{0.05} \\
\hline & 2 & 101.8 & & \\
\hline & 3 & 101.8 & & \\
\hline \multirow{3}{*}{150} & 1 & 100.8 & \multirow{3}{*}{100.93} & \multirow{3}{*}{0.15} \\
\hline & 2 & 100.9 & & \\
\hline & 3 & 101.1 & & \\
\hline
\end{tabular}

\section{Forced degradation study}

Specificity of the developed method in the presence of the degradants is shown by the forced degradation studies [4]. Degradation was carried out on standard drug, drug formulation as well as on the placebo. Out of the ten known impurities of Tenofovir Alafenamide Fumerate, none of them were reported at the retention time of Tenofovir (Table 8).

The developed method was validated for accuracy, precision, reproducibility, specificity, robustness in accordance with $\mathrm{ICH}$ guidelines [10].

Maximum absorbance was shown at $260 \mathrm{~nm}$ and hence this was the wavelength selected.

For the purpose of method development, many columns were employed. A satisfactory symmetric peak as well as separation between the main peak and the impurities peak was obtained using C-18 Inertsil ODS column $(100 \times 4.6 \mathrm{~mm}, 5 \mu)$ since Tenofovir alafenamide fumarate is a polar drug.

With regard to the drug pKa, Ammonium Acetate buffer of $\mathrm{pH} 6$ was selected. In order for the complete separation of all the 10 impurities of Tenofovir Alafenamide Fumarate, a solvent mixture (ACN:THF) in 30:70 ratio was added to the buffer in different ratios. The most optimum ratio was found to be when mobile phase A contained $1 \%$ solvent mixture and mobile phase B contained 50\% solvent mixture, the rest being buffer.

A retention time of 6.5 minutes was observed wherein the column oven temperature was set at $45^{\circ} \mathrm{C}$ and the sample temperature was $8^{\circ} \mathrm{C}$. However, in order for the elution of all the impurities, a run time of 15 minutes was opted.

Once all the method parameters were optimized, stability of the method was determined by performing forced degradation studies. Degradation by acid, base, peroxide, water, humidity and heat was done. Degradation of drug substances between $5 \%$ and $20 \%$ has been accepted as reasonable for validation of chromatographic assays and the observed values of degradation were within this limit suggesting that the developed method was stable. After the establishment of the stability of the method, validation parameters such as accuracy, linearity, precision, system suitability and robustness were evaluated. With the flow rate of $1.5 \mathrm{~mL} / \mathrm{min}$, the method was found to be accurate, precise and linear within a range of $10 \mathrm{ppm}-150 \mathrm{ppm}$. Robustness studies as well as filter validation studies were performed indicating that the developed method is rugged.

Hence, the aim of developing a stable method along with its validation was achieved for Tenofovir alafenamide fumarate.

\section{Conclusion}

A simple, precise and specific RP-HPLC assay method was 
Citation: Aggarwal NN, Bhat KI, Jacob JT (2018) Stability Indicating Assay Method Development and Validation for Tenofovir Alafenamide Fumarate by RP-HPLC. Pharm Anal Acta 9: 601. doi: 10.4172/2153-2435.1000601

Page 6 of 6

\begin{tabular}{|c|c|c|c|c|c|c|}
\hline \multirow{2}{*}{ Stress } & \multirow{2}{*}{ Conditions } & \multirow{2}{*}{ \% Degradation } & \multicolumn{2}{|c|}{ TAF } & \multirow{2}{*}{ Purity Flag } & \multirow{2}{*}{ Acceptance Criteria } \\
\hline & & & Purity Angle & Purity Threshold & & \\
\hline Initial & & - & 0.106 & 0.295 & No & \multirow{7}{*}{$\begin{array}{l}\text { The Purityangle should be } \\
\text { less than Purity Threshold } \\
\text { and no purity flag for Tenofovir } \\
\text { Alafenamide Fumarate peak. }\end{array}$} \\
\hline $\begin{array}{c}\text { Acid Stress } 0.1 \\
\mathrm{~N} \mathrm{HCl}\end{array}$ & $2 \mathrm{~min}, 2.5 \mathrm{~mL}, \mathrm{BT}$ & 9.6 & 0.134 & 0.302 & No & \\
\hline $\begin{array}{c}\text { Peroxide Stress } \\
30 \% \mathrm{H}_{2} \mathrm{O}_{2}\end{array}$ & $2.5 \mathrm{~mL}, 3.5$ hours & 8.4 & 0.126 & 0.213 & No & \\
\hline $\begin{array}{c}\text { Base Stress } \\
0.05 \mathrm{~N} \mathrm{NaOH}\end{array}$ & $2 \mathrm{Min}, 0.5 \mathrm{~mL}$ & 8.7 & 0.129 & 0.314 & No & \\
\hline Humidity stress & $40^{\circ} \mathrm{C} / 75 \% \mathrm{RH} 7$ days & 7.4 & 0.106 & 0.3 & No & \\
\hline Water stress & $80^{\circ} \mathrm{C}, 3.5$ hours & 18.6 & 0.129 & 0.228 & No & \\
\hline Thermal stress & $105^{\circ} \mathrm{C}, 1$ hour & 6.9 & 0.14 & 0.313 & No & \\
\hline
\end{tabular}

Table 8: Forced degradation study.

developed for estimation of TAF and validated for determination in commercial tablet dosage form of $25 \mathrm{mg}$. The procedure was validated for all compendial and non compendial parameters in accordance with ICH guidelines. The study showed that the reverse phased liquid chromatography is sensitive and selective for detecting TAF and its impurities. The method was validated by using various validation parameters like system suitability, specificity, linearity, precision, accuracy, solution stability, filter interference and robustness. All the validation parameters were found to be within the acceptance criteria. Stress studies were performed under acid, base, thermal, hydrolysis and humidity conditions. The method developed could detect the main peak without any interference from the degradant peaks formed under these conditions. The HPLC method was found to be accurate, precise and reproducible. The method can be applied for routine estimation of TAF in pharmaceutical formulations.

\section{Acknowledgements}

The authors are thankful to authorities of Mylan laboratories, Hyderabad and NGSM Institute of Pharmaceutical Sciences, Nitte (Deemed to be University), Mangalore for providing all the necessary facilities.

\section{References}

1. https://www.drugbank.ca/

2. Ettre LS (1993) Nomenclature for chromatography (IUPAC Recommendations 1993). Pure Appl Chem 65: 819-872.
3. Bakshi M, Singh S (2002) Development of validated stability-indicating assay methods-critical review. J Pharm Biomed Anal 28: 1011-1040.

4. Sanjay B, Dinesh S, Neha S (2012) Stability testing of pharmaceutical products. J Appl Pharm Sci 02: 129-138.

5. Badgujar BP, Mahajan MP, Sawant SD (2017) Development and validation of RP-HPLC method for the simultaneous estimation of tenofovir alafenamide and emtricitabine in bulk and tablet dosage form. Intl J of Chem Tech Res 10: 731739 .

6. Varanasi MB, Mohammed I (2017) Stability indicating RP-UPLC-PDA method development, validation of multi drug combination of emtricitabine, tenofovir alafenamide and rilpivirine in bulk drug and its tablet formulation. Oriental $\mathrm{J}$ Chem 33: 925-929.

7. Akram NMD, Umamahesh MA (2017) New validated RP-HPLC method for the determination of emtricitabine and tenofovir af in its bulk and pharmaceutical dosage forms. J Chem Pharm Sci 10: 54-59.

8. Gandla KS, Rajkumar M, Pranay K, Sudheer KD (2017) New stability indicating RP-HPLC method for the simultaneous estimation of tenofovir alafenamide and emtricitabine in bulk and combined tablet dosage forms. Asian J Pharm Anal Med Chem 5: 142-149.

9. Szepesi G, Gazdag M, Mihalyfi K (1991) Selection of high-performance liquid chromatographic methods in pharmaceutical analysis: III. Method validation. $J$ Chrom A 464: 265-278.

10. Bhavana N, Likhitha P, Hanumanth, Suresh $P$ (2017) Design and development of stability indicating assay methods as per $\mathrm{ICH}$ guidelines-a review. Int $\mathrm{J}$ Pharm Chem Res 3: 252-258. 